\title{
O ensino de Matemática no pensamento de Comênius, Pestalozzi e Montessori
}

\section{The teaching of Mathematics in the thinking of Comenius, Pestalozzi and Montessori}

\author{
Olivia Morais Medeiros Neta* \\ Liliane dos Santos Gutierre**
}

\begin{abstract}
RESUMO
Neste artigo, discutimos os fundamentos para o ensino da Matemática na Pedagogia Tradicional e na Pedagogia Nova, marcadamente, a partir das teorias de fronteira de Comenius, Pestalozzi e Montessori. Esta pesquisa é de cunho documental e bibliográfico. Ao final da análise, concluímos que: há uma circulação de ideias entre o pensamento educacional de Comenius, Pestalozzi e Maria Montessori no que diz respeito ao uso de materiais didáticos e que nos métodos por estes pensadores a Matemática está associada às atividades práticas e gradativas.
\end{abstract}

Palavras-chave: Fundamentos da Educação. Matemática. Comenius. Pestalozzi. Montessori.

\begin{abstract}
In this article, we discuss the fundamentals for the teaching of Mathematics in Traditional Pedagogy and New Pedagogy, markedly, based on theories of Comenius, Pestalozzi and Montessori. This research is documental and bibliographic. At the end of the analysis, we conclude that: there is a circulation of ideas between the educational thoughts of Comenius, Pestalozzi
\end{abstract}

${ }^{*}$ Universidade Federal do Rio Grande do Norte. Natal, Rio Grande do Norte, Brasil. E-mail: olivianeta@gmail.com - http://orcid.org/0000-0002-4217-2914

${ }^{* *}$ Universidade Federal do Rio Grande do Norte. Natal, Rio Grande do Norte, Brasil. E-mail: lilianegutierre@gmail.com - http://orcid.org/0000-0001-6124-7769 
and Maria Montessori regarding the use of didactic materials and that in the methods proposed by these thinkers Mathematics is associated with practical and gradual activities.

Keywords: Fundamentals of Education. Mathematics. Comenius. Pestalozzi. Montessori.

\section{Introdução}

No Brasil, o biênio 2017 e 2018 foi denominado de "Biênio da Matemática", uma vez que o país sediou a Olimpíada Internacional da Matemática, o Congresso Internacional de Matemática e que o Conselho Nacional de Desenvolvimento Científico e Tecnológico (CNPq) definiu como tema central da Semana de Ciência e Tecnologia do ano de 2017 "A matemática está em tudo".

Diante de tal protagonismo, na condição de professores que formam professores de Matemática ou Pedagogos atentos aos fundamentos históricos e filosóficos da educação, nos propusemos a discutir elementos para o ensino da Matemática na Pedagogia Tradicional e na Pedagogia Nova, ${ }^{1}$ marcadamente a partir das teorias de fronteira de Comenius, Pestalozzi e Montessori, ${ }^{2}$ na tentativa de refletir e responder aos questionamentos: “Como se ensina Matemática?” E, que "Matemática se ensina?"

A justificativa para a escolha dos pensadores, remete a interface que eles têm entre formas distintas de pensar o ensino. Sendo, Comenius vinculado à Pedagogia Tradicional, considerando que ele corroborou e vivenciou mudanças no contexto escolar e nos hábitos de ensino em vigor. Pois, crescia “[...] o número de escolas que acolhem mais crianças, cuja presença é um pouco mais assídua. Os mestres criam um novo saber-fazer para resolver os problemas diários. Esse saber-fazer codificado atinge não só os conteúdos a ensinar, mas também todos os aspectos da vida da classe"3 (GAUTHIER, 2014, p. 155). Já Pestalozzi e Montessori constituem-se como agentes do processo de uma Pedagogia Nova,

1 Segundo Gauthier (2014) a pedagogia, cujo nascimento teria ocorrido no século XVII, se manteve de uma maneira relativamente estável até o século XIX, tanto no seu espírito quanto nas suas práticas, para constituir uma espécie de tradição pedagógica na Europa. É neste contexto que situa-se a pedagogia tradicional e, de maneira mais estrita, a pedagogia nova a partir do séuclo XIX.

2 Ao longo do texto apresentamos e discutimos ideias dos referidos pensadores da educação.

3 Tais considerações remetem ao ensino simultâneo, códigos orientando a postura, os deslocamentos, as punições, o lugar de cada aluno na sala etc. 
a qual "[...] se torna, pois, para esses autores do fim do século XIX e começo do XX, não só uma ciência, mas uma ciência aplicada, cujo destino está ligado ao estado do progresso dos conhecimentos fundamentais em psicologia" (GAUTHIER, 2014, p. 165).

De acordo com Gauthier (2014), a pedagogia, cujo nascimento teria ocorrido no século XVII, se manteve de uma maneira relativamente estável até o século XIX, tanto no seu espírito quanto nas suas práticas, para constituir uma espécie de tradição pedagógica na Europa. É neste contexto que se situa a Pedagogia Tradicional e, de maneira mais estrita, a Pedagogia Nova ${ }^{4}$ a partir do século XIX imprimindo novas concepções de ensino.

Desta maneira, a partir da inter-relação das teorias de Comenius, Pestalozzi e Montessori com autores contemporâneos da área da Educação e da Educação Matemática refletimos sobre o ensino de Matemática na Pedagogia Tradicional e na Pedagogia Nova.

\section{Um olhar sobre o ensino e a Matemática em Comenius}

João Amós Comenius (1592-1671), ao qual chamaremos de Comenius, nasceu em Morávia (região da atual República Tcheca) e vivenciou o século XVII, que foi considerado por historiadores, um século trágico, confuso, problemático, mas que preconizou transformações, inclusive, no que se refere à Pedagogia, uma vez que, a partir de Comenius

[...] se delineiam pela primeira vez de maneira orgânica e sistemática alguns dos problemas já relevantes da Pedagogia: desde o projeto antropológico-social que deve guiar o mestre até os aspectos gerais e específicos da didática, para chegar às estratégias educativas referentes às diversas orientações da instrução (CAMBI, 1999, p. 281).

Cambi (1999) nos diz que Comenius escreveu, inicialmente, textos de caráter de divulgação, com o objetivo de que o povo tcheco conhecesse sua própria história, contudo, ao avançar nos escritos, escreveu diversas obras que 
se voltaram para a importância do processo educativo, uma vez que ele considerava a educação como um "caminho para a salvação, uma formação para a vida eterna" (COMENIUS, 1966).

Comenius foi obrigado a deixar sua terra natal em função de lutas políticas e religiosas que aconteciam em Morávia, de modo que no período em que ficou exilado - 1628 a 1632 - escreveu a Didática Tcheca, que, ao ser traduzida para o latim, em 1957, recebeu o nome de Didática Magna, buscando por meio dessa, construir "uma ciência universal capaz de produzir aquela pacificação geral entre os homens que constitui a aspiração última da sua vida" (CAMBI, 1999, p. 286).

Com a Didática Magna, Comenius sistematizou um saber estritamente pedagógico. Segundo Boto (2019), nesta obra Comenius pretendia compreender o percurso do aprendizado, sugerindo que as escolas organizassem suas metas, sua disciplina e seu método de aprendizado, bem como o ritual de ensino. Assim, Comenius edificou o seu projeto educativo, se tornando o primeiro sistematizador do discurso pedagógico, relacionado organicamente os aspectos técnicos da formação com uma reflexão sobre o homem (CAMBI, 1999).

$\mathrm{O}$ método apresentado por Comenius inspira-se diretamente no preceito cartesiano segundo o qual cada etapa de processo de aprendizagem deverá supor o encadeamento de conteúdos, partindo do simples para o complexo, do geral para o particular. E, o ensino ocorreria com os alunos divididos por classes separadas na sala de aula perante critério de nível de aprendizado dos estudantes (BOTO, 2019).

Em seu método, Comenius preconizava o professor como figura central, uma vez que caberia aos alunos escutarem e obedecerem, sendo essa uma "educação mecanicamente programada", mas também uma pedagogia preocupada com a comunicação, sendo eficaz, natural e intuitiva. Embora, no que se refere à compreensão psicológica do processo de ensino e aprendizagem, as ideias de Comenius tenham sido superadas, elas foram consideradas um avanço para a época, por propor, grandiosamente, uma escola para todos, mesmo diante à dominação da igreja católica que, como sabemos, no período conhecido como estiagem, voltava-se à formação das classes dirigentes (NARODOWSKI, 2001).

Além disso, vale dizer que ele

[...] avança uma proposta de organização escolar que prevê quatro graus sucessivos, para cada um dos quais delineia os objetivos, os conteúdos e os métodos, com uma meticulosidade e uma minúcia por vezes excessivas, que desembocam na repetividade e no pedantismo (CAMBI, 1999, p. 290). 
Neste sentido, Narodowski (2001, p. 56) exprime que, na Didática Magna Comenius oferece um esquema metodológico pelo qual "[...] se poderá educar a juventude e pelo qual se chegará a ter a escola que até então não houvera". Sendo o interesse de Comenius o de "“...] normatizar os elementos indispensáveis que haverão de constituir o modelo buscado; e seu interesse é que tal modelo seja internamente harmonioso. A ordem alcançada através da racionalidade é a idéia condutora; essa tem, como propósito, a boa disposição dos elementos" (NARODOWSKI, 2001, p. 56).

Desta feita, ensinar tudo a todos se configurou como a utopia comeniana a qual possuía algumas prescrições didáticas, a exemplo: a) clareza; b) ir do geral ao particular; c) avanço gradual; d) aprender o que é útil. Nesta utopia, perguntamos: qual o lugar da Matemática?

Comenius, na Didática Magna, apontava a importância de se usar diversos materiais nas aulas de Matemática, havendo, inclusive, recomendações para que fossem construídos modelos para ensinar Geometria. E, no ano de 1650, Comenius publicou o livro Orbis Sensualium Pictus, a partir do qual sugere o estudo de temas diversos a partir do uso de imagens.

\section{FIGURA 1 - ORBIS SENSUALIUM PICTUS, DE COMÊNIUS (1658).}

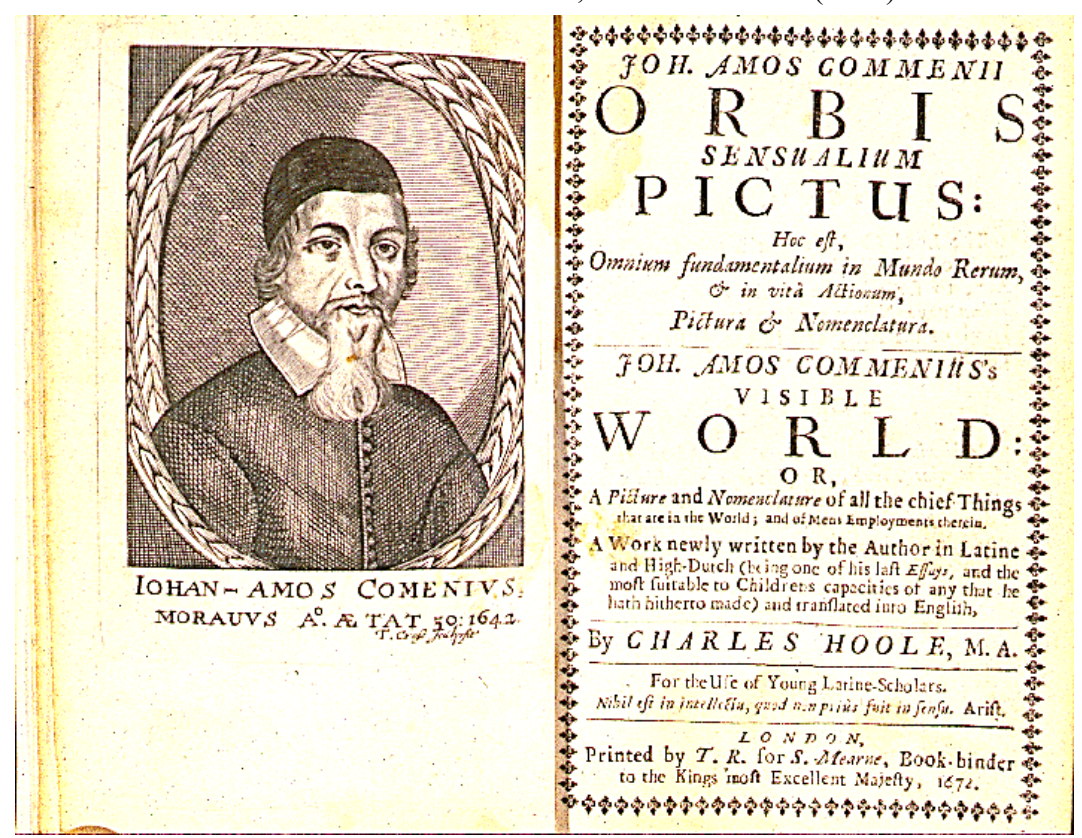

FONTE: Disponível em: https://archive.org/stream/cu31924032499455\#page/n165/mode/2up/ search/arit. Acesso em: 04 jan. 2019. 
No livro Orbis Sensualium Pictus ${ }^{5}$, Comenius destinou uma das lições ao estudo da Geometria. Nesta lição, há a indicação de estudo da definição da Geometria. Os conteúdos sobre linhas, círculos, quadrantes, triângulos, quadrados e outras figuras são apresentados a partir de associação com números de referência em uma figura.

FIGURA 2 - LIÇÃO DE GEOMETRIA NO LIVRO ORBIS SENSUALIUM PICTUS, DE COMÊNIUS (1658).

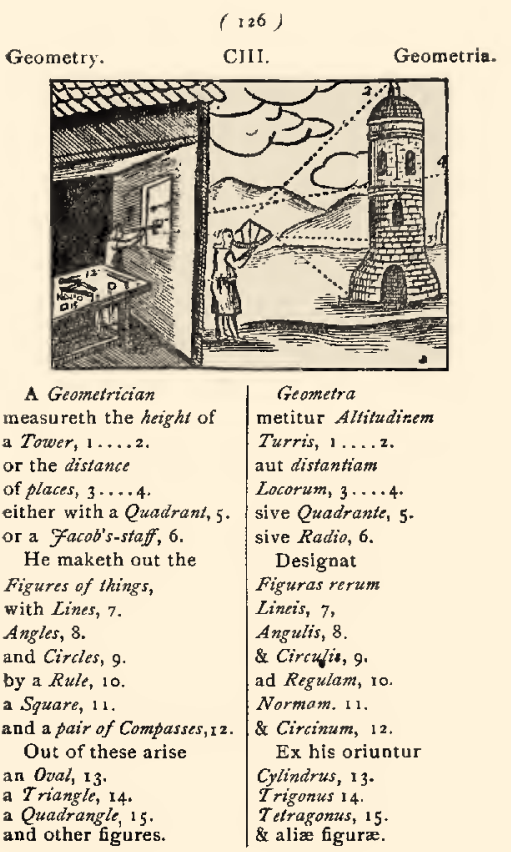

FONTE: Disponível em: https://archive.org/stream/cu31924032499455\#page/n165/mode/2up/ search/arit. Acesso em: 4 jan. 2019.

Na figura 2, há a apresentação de um geômetra analisando desenhos e cálculos geométricos em uma oficina e um sujeito em ambiente externo fazendo uso de teodolito para medir ângulos em direção a uma torre. Ainda pela figura 2, percebemos que o mundo que cerca os homens é valorizado por Comenius

5 "Orbis Pictus", concebido em Sárospatak, na Hungria, em 1657 e publicado em 1658, em Nuremberg, é considerado o primeiro livro didático ilustrado e a primeira cartilha do mundo cristão ocidental. Foi utilizado na Europa reformista durante mais de dois séculos após sua publicação (CAMBI, 1999). 
durante a aprendizagem matemática, na medida em que as observações feitas para se obter medidas de ângulos, ou para se perceber formas geométricas, são realizadas por meio da curiosidade, da investigação, da admiração, da experiência (enquanto experimento).

Este entendimento alinha-se ao ideal de ensinar tudo a todos, pois esse ideal consiste em ensinar sob os parâmetros racionais da ordenação com a ambição de equiparar os conteúdos destinados à transmissão dos saberes no espaço concreto da escola. Pois, para Comenius, tudo aquilo que está no mundo visível é conveniente para que a escola forme o homem para isso. E, neste sentido, a geometria foi utilizada para a leitura do mundo, uma vez que se consideram os conteúdos sobre linhas, círculos, quadrantes, triângulos, quadrados e outras figuras presentes no mundo dos homens.

Assim, os elementos matemáticos corroborariam com o princípio de transferibilidade, defendido por Comenius, o qual corresponde a regra geral de formar o homem nos fundamentos das principais coisas que existem e são criadas.

E, considerando as contribuições de Comenius aos fundamentos para o ensino da Matemática no contexto das ideias da Pedagogia Tradicional, nas próximas seções discutiremos as ideias de Pestalozzi e Montessori no que se refere ao ensino de Matemática na Pedagogia Nova.

\section{Um olhar sobre o ensino e a Matemática em Pestalozzi}

Johann H. Pestalozzi (1746-1827), nascido em Zurique na Suíça, teve seu pensamento marcado pela influência de Jean-Jacques Rousseau ${ }^{6}$ e a valorização da natureza, enxergando a atividade na educação como sendo uma das melhores ferramentas para que a criança pudesse mostrar toda a sua potencialidade ${ }^{7}$ (ARCE, 2002).

O pensamento educacional de Pestalozzi está associado às experiências dele como educador com a criação de escolas, a partir das quais delineou o seu método de ensino com a interligação entre a mão, o coração e o cérebro. Assim, os princípios do método remetem a:

6 Para Gauthier (2014), Jean-Jacques Rousseau foi um dos principais pensadores do século XVIII e sua influência ainda se faz sentir em nossos dias. Sua concepção educativa é funcional, implicando uma visão exclusivamente utilitarista da cultura: a criança só deve aprender aquilo que lhe será diretamente útil durante a sua existência.

7 A ânsia de espalhar seu método, levou Pestalozzi a escrever uma série de cartas e livros, dos quais destacam-se: Leonardo e Gertrudes (1781); Como Gertrudes ensina seus filhos (1801); O canto do Cisne (1827). 
1. Primeiro, toda a verdadeira reforma deve começar com o indivíduo e não com a sociedade. [...];

2. Segundo, o indivíduo só pode ser elevado dando-lhe poder de se tornar auto-suficiente. [...] o melhor serviço que a sociedade pode prestar para o indivíduo é ensiná-lo, primeiro, a respeitar-se, e segundo, a amparar a si mesmo;

3. Terceiro, o único meio de atingir o fim desejado é através do desenvolvimento. As sementes de ação independente, latentes em toda criança, estão, apenas, esperando uma oportunidade de crescer. A educação deve oferecer a oportunidade para este crescer (EBY, 1962, p. 383-384).

Tröhler (2014) discorre sobre as experiências educativas realizadas por Pestalozzi e a organização de seu método e ressalta que o educador valorizava o ensino de línguas para que as crianças pudessem verbalizar suas impressões do mundo. Destaca ainda que Pestalozzi deu importância mais teórica à formação profissional e uma importância mais prática para a educação moral elementar. Assim, Pestalozzi definiu seu método e estabeleceu que a melhor educação é a que acompanhe o desenvolvimento evolutivo da criança.

Pestalozzi, em Argóvia, instalou o centro educativo de nome Neuhof (1770-1780), o qual era destinado para a educação de meninos pobres que também trabalhavam na fiação e tecelagem de algodão. Tempos depois, Pestalozzi transformou o castelo de Yverdun, em Neufchâtel, na Suíça Francesa, num centro de experimentação e de construção das suas ideias educacionais (OLIVEIRA, 2017).

Para Eby (1962), cada centro de educação fundado por Pestalozzi foi uma "escola experimental". Sendo que, as duas principais instituições que lhe deram fama foram o instituto em Burgdorf, de 1800 a 1804, e, um outro semelhante, em Yverdun, de 1805 a 1825.

Considerando essas experiências, Pestalozzi, em carta de 16 de outubro de 1821, em Yverdon, exprime que

Toda a verdadeira força interior do pensamento e da ruminação, mesmo do pensamento e da ruminação dentro do divino e do sagrado, é fundamentada na existência e se prova forte por esta ação. O esforço em toda boa ação da existência, o esforço incansável no cumprimento dos deveres e na superação de si mesmo em todas as direções, que requer tal esforço, é então verdadeiramente o maior sacrifício de fé e gratidão que você pode trazer ao Criador do mundo. Os seus dons e disposições. Na 
verdade, na verdade, esta é a oração mais importante. Santo que pode levantar-se da força profunda do seu coração crente e amando a Deus teu Pai (PESTALOZZI, 2009, p. 152, tradução nossa).

Desse modo, afirmava a ideia de que a partir da ruminação e leitura de mundo com observação, manipulação e experimentação das coisas a criança iria construir conceitos. Com isso, a arte da instrução elementar pestalozziana estaria presente também na seleção dos objetos adequados para a observação ativa. Nesses termos, o número, a forma e a palavra são os pilares de sustentação e origem de todo conhecimento do homem (SOËTARD, 2010).

Para Röhrs (2010, p. 69), Pestalozzi na Sexta Carta ressalta que o "número, forma e linguagem são ao mesmo tempo os meios de ensino elementar como a soma das outras propriedades externas, de um objeto que se reúne no círculo do seu contorno e nas relações de suas propriedades numéricas, e que são assimiladas pela minha consciência por meio da língua".

Os números são, em essência, abstrações de magnitude; por conseguinte, é necessário que precedam ou que acompanhem, ao mesmo tempo, os elementos da aritmética com os fundamentos iniciais do desenho, eis a experimentação. Para ele, as intuições e realizações das primeiras divisões do número com representações, aumentadas ou diminuídas, de objetos reais; depois, com pontos determinados, nos quais não aceita a criança como número as formas reais, mas que pode comprovar e experimentar na realidade dos pontos mesmo da realidade das relações numéricas.

Para Mesquida (2016), Pestalozzi

[...] alimenta e realiza a integralidade do ser humano: mente, sentimento, ação. Ou, ainda, intelecto, sentimento e ação. Modernamente, poderia ser traduzida pela fórmula saber pensar, saber sentir, saber agir, sendo que o saber pensar é nutrido pelo sentir assim como o saber agir tem sua fonte dinâmica no coração (MESQUIDA, 2016, p. 21).

Pestalozzi, sem dúvida, conferiu um lugar central ao número e à sua aprendizagem. Por ele, novas formas de abordar o ensino da Aritmética foram propostas e seus alunos obtinham resultados surpreendentes na aprendizagem do cálculo (GALLEGO, 2005).

Para Pestalozzi, "a Aritmética, em si, traz em toda sua origem a habilidade de agregar e retirar unidade/número de várias coisas da natureza” (PESTALOZZI, 
1980, p. 176, tradução nossa) ${ }^{8}$. Para ele, a arte de conhecer um objeto a partir da representação de quantidade (do número) não é nada mais nada menos que uma abreviação do cálculo.

Pestalozzi considerava o número como um dos três meios elementares para a obtenção do conhecimento e, por isso, dedicou atenção especial à sua aprendizagem. Enquanto a palavra e a forma necessitam do número para poder apresentar-se como intuições claras, considerava o número como único meio que não tem nenhuma subordinação.

E, de acordo com Costa (2014), os primeiros exercícios indicados para as crianças consistiam em perguntar pela quantidade de múltiplas coleções: partes do corpo, objetos desenhados, dedos, pedrinhas, objetos que se tem a mão. Assim, propunha-se que as crianças resolvessem estas questões pela contagem, que aprendiam por imitação, vendo as pessoas adultas, em particular a mãe, contar distintas coleções propostas.

Também se usava como coleções as tábuas de silabação e, dessa forma, unia-se a aprendizagem dos números ao das palavras. A aprendizagem das palavras baseava-se nos números, pois se perguntava para a criança pela quantidade de sílabas de cada palavra e pela pronúncia das quais ocupavam o primeiro lugar, o segundo lugar, entre outros (INCONTRI, 1996). Aparece aqui outro tipo de exercício cuja resposta é um número ordinal, que se achava auxiliado também pela contagem neste contexto.

As primeiras coleções tinham no máximo dez elementos e sobre elas realizavam-se diferentes exercícios que pretendiam ser uma iniciação as operações aritméticas. Posteriormente, quando o aluno compreendesse as adições de uma e uma unidade até dez e quando aprendesse expressá-las com facilidade, retomava-se o questionário, mas variava-se a pergunta:

Cuando tú tienes dos tablitas, ¿cuántas veces tienes una tablita?”- El niño mira, cuenta y responde exactamente: "Cuando yo tengo dos tablitas, tengo dos veces una tablita. ¿Cuántas veces uno son dos?, ¿cuántas unos son tres?, etc. ¿Cuántas veces está contenido uno en dos?, ¿en tres? (PESTALOZZI, 1980, p. 107).

8 Na obra Primeiras Lições de Coisas (1861), de Norman A. Calkins, a composição metodológica é ancorada nos princípios educacionais do método de ensino intuitivo de Pestalozzi. Oliveira (2017) se dedicou a análise de como se deu o ensino de número através das ideias pedagógicas sistematizadas por Pestalozzi (as quais foram apropriadas e incorporadas por Calkins na composição do seu manual pedagógico). 
Tão logo o aluno conhecesse a forma simples e elementar da adição, da multiplicação e da divisão e tivesse se familiarizado, por meio da intuição, com a natureza das formas de cálculo, procurava-se fazer, por meio de outro exercício, conhecer e tornar familiar a forma original da subtração:

Se quita una de las diez tablitas que se han sumado y se pregunta: 'Cuando de diez has quitado uno ¿cuántos quedan?'- El niño cuenta, encuentra nueve y responde: 'Cuando de diez he quitado uno, quedan nueve'. Se quita en seguida la segunda tablita y se pregunta: 'Uno quitado de nueve, ¿cuántos son?' - El niño cuenta de nuevo, encuentra ocho y responde: 'Uno quitado de nueve son ocho'. Así se continúa hasta el fin (PESTALOZZI, 1980, p. 107).

Os exercícios sobre os dez primeiros números foram incluídos por Pestalozzi no Libro de las madres e correspondiam, portanto, ao ensino para as crianças em suas brincadeiras. Ressaltamos que, como o Libro de las madres era usado na escola de Pestalozzi, "os exercícios comentados possivelmente deveriam ser os primeiros que realizavam seus alunos ao começar sua educação" (COSTA, 2014, p. 47).

FIGURA 3 - TÁBUA N. 1 DE PESTALOZZI. NÚMEROS ATÉ CEM, REMETENDO À IDEIA DAS RELAÇÕES QUE EXISTEM ENTRE ELES.

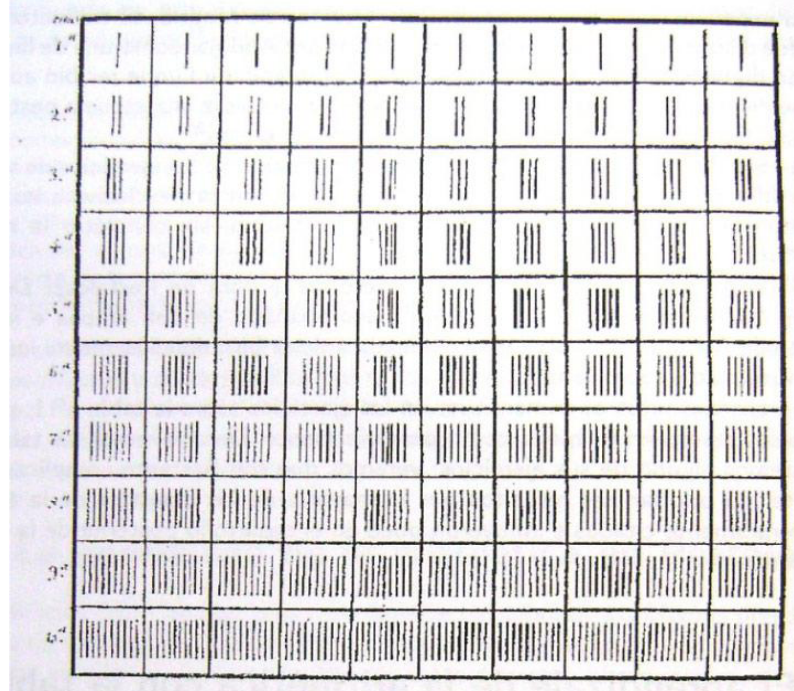

FONTE: Chavannes (1809, p. 204). 
Por meio do uso dessa tábua, podem ser feitos oito diferentes tipos de exercícios, que devem ser abordados de forma sucessiva, pois formam uma graduação. Em todos eles se recorre à tábua por filas, considerando as diferentes relações entre as quantidades que representam os rabiscos.

O uso dessa tábua admitia que a criança exercitasse a capacidade de ver o traço como unidade e estabelecesse as relações entre essas unidades. Oliveira (2017) nos diz que para alcançarmos o primeiro objetivo, era preciso pedir à criança que reproduzisse quatro traços na lousa e que escrevesse o algarismo 4; cinco traços e escrever o algarismo 5, e assim por diante, pois "reproduzir traços era também o momento de escrever algarismos" (OLIVEIRA, 2017, p. 1026). Além disso, observando essa tábua, o professor poderia fazer questões envolvendo operações de adição, subtração, multiplicação e divisão, mentalmente, sem a necessidade do registro dos signos $(+,-, \times, \div)$. Sobre isso, Chavannes nos dá um exemplo:

[...] 'quantas 37 vezes um são vezes 5?' Ao observar a tábua, a criança construiria a resposta. Saibamos como: ela iria para a quinta fileira e contaria 7 vezes os quadradinhos com 5 traços que são 35; para formar 37 vezes 1, ela avançaria mais dois traços do quadradinho seguinte (CHAVANNES, 1805, p. 32, tradução nossa).

Essa era para Pestalozzi uma forma simples e elementar do cálculo, de modo que a criança, segundo Chavannes (1805), o realizaria por fases. No início solicita-se que o aluno imite o professor, que realiza em primeiro lugar o exercício, e reconheça que a primeira fila da tábua está constituída por coleções de um rabisco, a segunda fila por coleções de dois rabiscos, a terceira fila de três e, assim, sucessivamente.

Depois de ter sido feito este exercício em uma fila, por exemplo, na terceira, pede-se outro, que consiste em ler a fila como coleção de três elementos, isto é, uma vez o três, duas vezes o três, quatro vezes o três. Esses exercícios se realizam a partir da imitação do professor, auxiliado pela contagem.

Assim, como nos aponta Oliveira (2017), os elementos da Geometria para Pestalozzi

[...] eram estudados a partir da forma e da medição, bem como do desenho linear e do desenho artístico sendo matérias independentes, 
mas subordinadas e articuladas às primeiras. Pelo método intuitivo a criança começava a estudar os elementos da Geometria a partir da forma (OLIVEIRA, 2017, p. 1019).

Os demais exercícios que são apresentados no texto de Chavannes (1809) têm grau maior de dificuldade, mas tomam sempre os traços e as casas como unidades.

FIGURA 4 -TÁBUA N. 2. DE PESTALOZZI. DEZ FILAS COM DEZ QUADRADOS IGUAIS EM CADA UMA DELAS. AS DA $2^{\text {a }}$ FILA ESTÃO DIVIDIDAS EM METADES POR UM TRAÇO VERTICAL, COM OS DA $3^{\text {a }}$ FILA EM TERÇOS, OS DA $4^{\mathrm{a}}$ FILA EM QUARTOS E ASSIM ATÉ OS DA $10^{\mathrm{a}}$ FILA, QUE ESTÃO DIVIDIDOS EM DÉCIMOS, SEMPRE MEDIANTE LINHAS VERTICAIS.

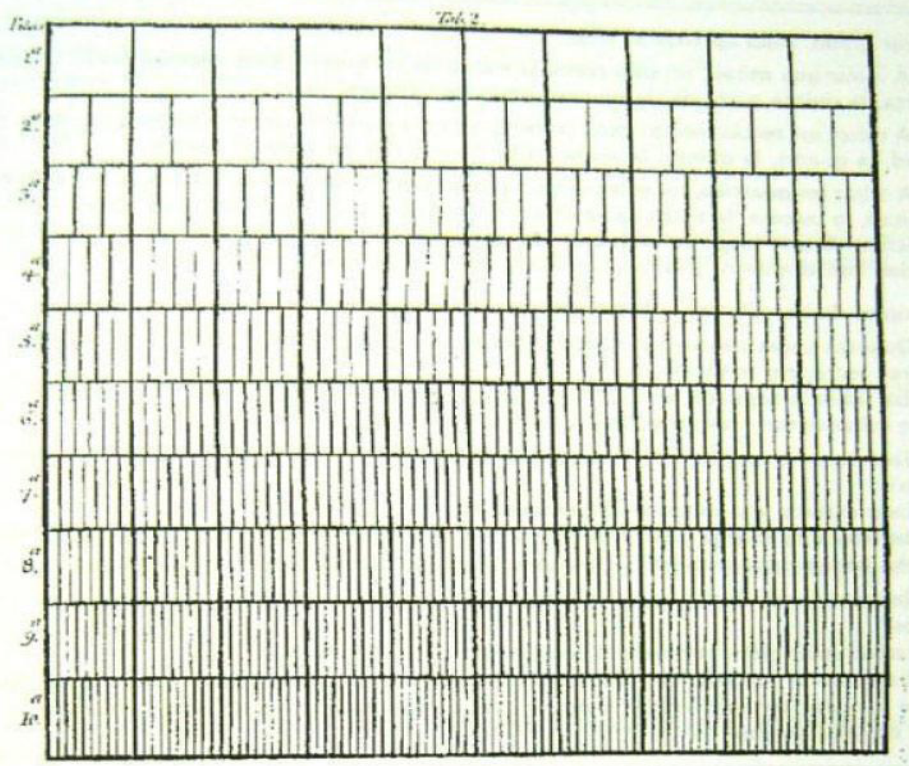

FONTE: Chavannes (1809, p. 206). 
FIGURA 5 - TÁBUAN. 3 DE PESTALOZZI É UMAAMPLIAÇÃO DA TÁBUAN. 2. CONTÉM 10 FILAS DE 10 QUADRADOS DIVIDIDOS POR LINHAS VERTICAIS E OS QUADRADOS DIVIDIREM-SE EM PARTES IGUAIS POR LINHAS HORIZONTAIS, SENDO: OS DA SEGUNDA COLUNA EM DUAS PARTES, OS DA TERCEIRACOLUNA EM TRÊS, ATÉ OS DA DÉCIMA COLUNA QUE SE DIVIDEM EM 10 PARTES IGUAIS.

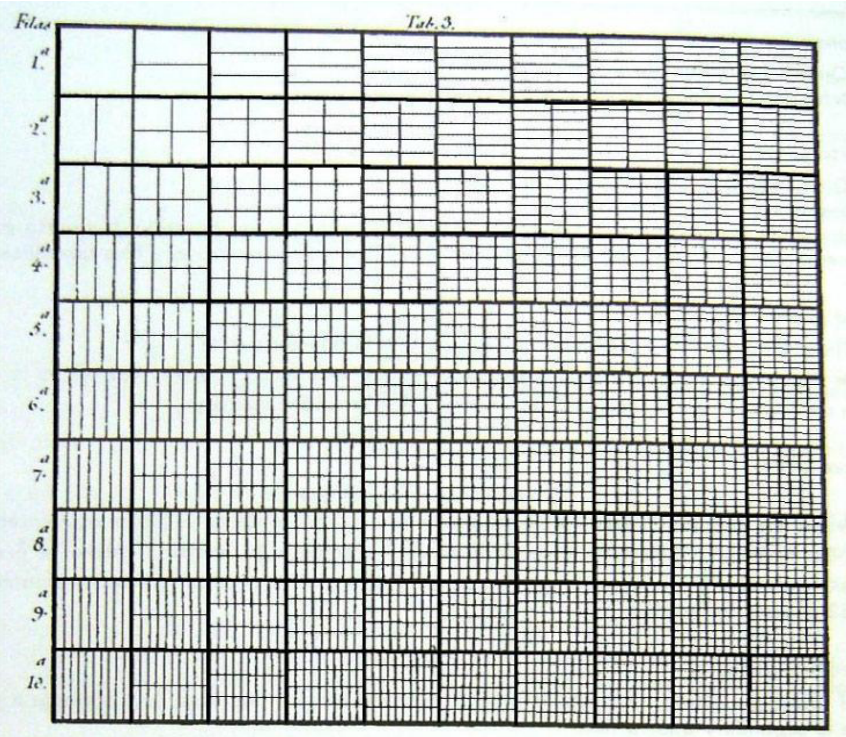

FONTE: Chavannes (1809, p. 208).

Costa ressaltou que,

Sobre esta tábua realizavam-se oito diferentes tipos de exercícios. A proposta de Pestalozzi, sobretudo no que se refere às tábuas n. 2 e 3 , era demasiadamente ambiciosa para o lugar que se conferia a Aritmética na escola, o que pode explicar o porquê não se generalizaram esses exercícios. Segundo Gallego (2005), a compreensão dos exercícios que Pestalozzi propunha para as tábuas n. 2 e 3 estavam fora do alcance da maioria dos professores de primeiras letras, que apenas chegavam a conhecer algumas operações com números inteiros (COSTA, 2014, p. 51). 
Por outro lado, em Oliveira (2017), encontramos que a criança, quando já familiarizada com os exercícios propostos na tábua 1 , avançava às partes das unidades, ou seja, estudava as frações. Pestalozzi $(2009$, p. 46) nos diz que "A linha reta é ainda aqui o meio mais simples e o mais fácil, aquela que se presta melhor à observação e à execução", pois, conforme Oliveira (2017, p. 1027) pode-se observar na figura que ao "dividir uma linha reta em medidas iguais é fazer a criança observar as partes ou frações de uma unidade". Logo as frações também tinham uma tábua, assim como no estudo de números. A análise da tábua $\mathrm{n}^{\mathrm{o}} 2$, tanto na vertical, quanto na horizontal, nos mostra que

[...] a noção de unidade inteira e fracionária também pode ser elucidada pela ideia de espaço. Por exemplo, olhando-a pela direção vertical, percebe-se que de cima para baixo os espaços entre as partes vão diminuindo. Já de baixo para cima, eles vão aumentando. Para além de outros aprendizados, essa tábua II propícia a criança aprender, através de cada quadradinho, quantas partes iguais são necessárias para compor uma unidade. À medida que o estudo vai avançando as frações vão sendo representadas por algarismos $(1 / 2 ; 1 / 3,1 / 4, \ldots)$ (OLIVEIRA, 2017, p. 1027).

Dessa maneira, o pedagogo suíço inspirou-se na proposta pedagógica de Comenius (Orbis sensualium Pictus, 1658), defensor da universalização da educação. Como Comenius, o pedagogo indicará o uso da imagem, como arte e como estratégia metodológica, para ensinar à criança a leitura e a escrita, como "técnica" didática importante (MESQUIDA, 2016).

Assim, podemos ver que no ensino de Geometria (linha reta, ângulo, ponto), o método indicado por Pestalozzi, já fazia associações com a aritmética, pois como vimos, por meio de figuras e traços (desenho), exaltando-se o concreto, buscava-se explicar o cálculo matemático, indo para além, das relações entre formas e medidas que a Geometria nos traz, mas associando a outros elementos que circundam esse conteúdo, como o cálculo com algarismos, múltiplos e submúltiplos do número, o sistema de numeração decimal.

\section{Um olhar sobre o ensino e a Matemática em Montessori}

Montessori nasceu na Itália em 1870 e faleceu nos Países Baixos, em 1952. Desde cedo se interessou pelas ciências e estudou medicina na universidade de 
Roma. Posteriormente, ao se especializar em psiquiatria, se interessou por estudos acerca de crianças com retardo mental. De acordo com Foschi (2012), Maria Montessori foi médica, psiquiatra, antropométrica, "especialista" em psicologia experimental, professora, política, feminista, teosofista, leiga, católica. E, cada um desses campos, em um certo sentido, possuem elementos que encontramos nas suas aplicações e no seu método.

Influenciada por Pestalozzi, Maria Montessori dedicou-se a educação e sistematizou um método, Método Montessori (1907), no qual o afeto e a afetividade constituem-se como bases para o Método Montessori.

Para Foschi (2012, p. 13), uma das chaves de leitura do Método Montessori está no "papel fundamental que as ciências do comportamento, incluindo as ciências experimentais, têm desempenhado na gestão social das sociedades liberais modernas". Neste sentido,

[...] desde os primeiros cursos sobre o seu Método, dados a partir de 1909, [Maria Montessori] dedicou o ciclo inicial de lições à psicologia e antropologia, salientando que estas ciências, que não estão ligadas ao laboratório abstrato, mas deve conduzir a uma nova pedagogia consistente com a investigação científica. Na verdade, da leitura do Método, pode-se deduzir um uso original das leis relativas a fisiologia dos sentidos e o recurso às teorias de ciências experimentais, especialmente com o objetivo de formar metodologicamente os professores (FOSCHI, 2012, p. 13).

O método montessoriano é biológico por se fundamentar em informações cientificas sobre o desenvolvimento infantil. Nesse método, as crianças conduzem seu próprio aprendizado e o professor fica atento para detectar a maneira particular de cada uma (MONTESSORI, 1965; 2013). Pari passu, o método 9 parte do concreto para o abstrato, de modo que a educadora desenvolveu materiais didáticos adequados para provocar o raciocínio da criança, por meio da mediação do professor.

9 Para Montessori (1965, p. 42), o método de observação há de fundamentar-se sobre uma só base: "a liberdade de expressão que permite às crianças revelar-nos suas qualidades e necessidades, que permaneceriam ocultas ou recalcadas num ambiente infenso à atividade espontânea. Enfim, é necessário que, simultaneamente ao observador, coexista também o objeto a observar; e se, por um lado, faz-se mister uma preparação para que o observador possa entrever e recolher a verdade, por outro, urge predispor as condições que tornam possível a manifestação dos caracteres naturais da criança". 
Para Costa (2001), método é "ativo, pois dá importância ao trabalho: as crianças devem cuidar da própria higiene e limpeza das salas. Empenha-se na individualização do ensino, estimulando a atividade livre concentrada e o principio da autoeducação" (COSTA, 2001, p. 2).

Sobre a relação de Maria Montessori com a Matemática e o ensino, ressaltamos a publicação das obras: Psicogeometria (1934) e Psicoaritmétrica (1934) que apresentam princípios para o ensino de Matemática e materiais pedagógicos (COSTA, 2001).

Para o método Montessori (2013), o uso de materiais concretos e o ensino de Matemática estariam indissociados e dessa relação viria os princípios de concreto-abstrato e a intuição no processo de construção de demonstrações.

$\mathrm{O}$ uso dos materiais concretos despertaria no aluno o potencial inventivo e aliando-o ao desejo de conhecer e de erguer o véu do universo que ainda lhe é desconhecido. Para Röhrs:

O material didático tinha igualmente a função de ajudar a criança a 'crescer na paz' a fim de que adquirisse um senso elevado de responsabilidade. Esse material, que constituía um dos elementos do 'ambiente preparado' da casa das crianças, era metodicamente concebido e padronizado, de maneira que a criança que tinha escolhido livremente se ocupar de um dos objetos propostos se encontrasse localizada em uma situação previamente determinada e fosse conduzida, sem saber, a encarar o seu desígnio intelectual (RÖHRS, 2010, p. 21).

Dentre os materiais didáticos desenvolvidos por Maria Montessori, um dos mais utilizados para o ensino de Matemática é o material dourado. Falzetta (1997, p. 1) descreve o material dourado ${ }^{10}$ como constituído por 500 cubinhos de $1 \mathrm{~cm} \times 1 \mathrm{~cm} \times 1 \mathrm{~cm}$, que representa a unidade; 100 barras de $1 \mathrm{~cm} \times 10 \mathrm{~cm}$ x $1 \mathrm{~cm}$, que representa a dezena; 10 placas de $1 \mathrm{~cm}$ x $10 \mathrm{~cm}$ x $10 \mathrm{~cm}$ e 1 cubo de $10 \mathrm{~cm}$ x $10 \mathrm{~cm} \times 10 \mathrm{~cm}$, que representa a unidade de milhar.

10 Hoje, alguns educadores preferem utilizar outra nomenclatura que não se prende ao valor representado, como os termos "cubinho" (unidade), "barra" (dezena), "placa" (centena) e "cubão" (milhar) (FALZETTA, 1997, p. 1). 
FIGURA 6 - MÉTODO MONTESSORIANO. CRIANÇAS USANDO MATERIAL DOURADO.

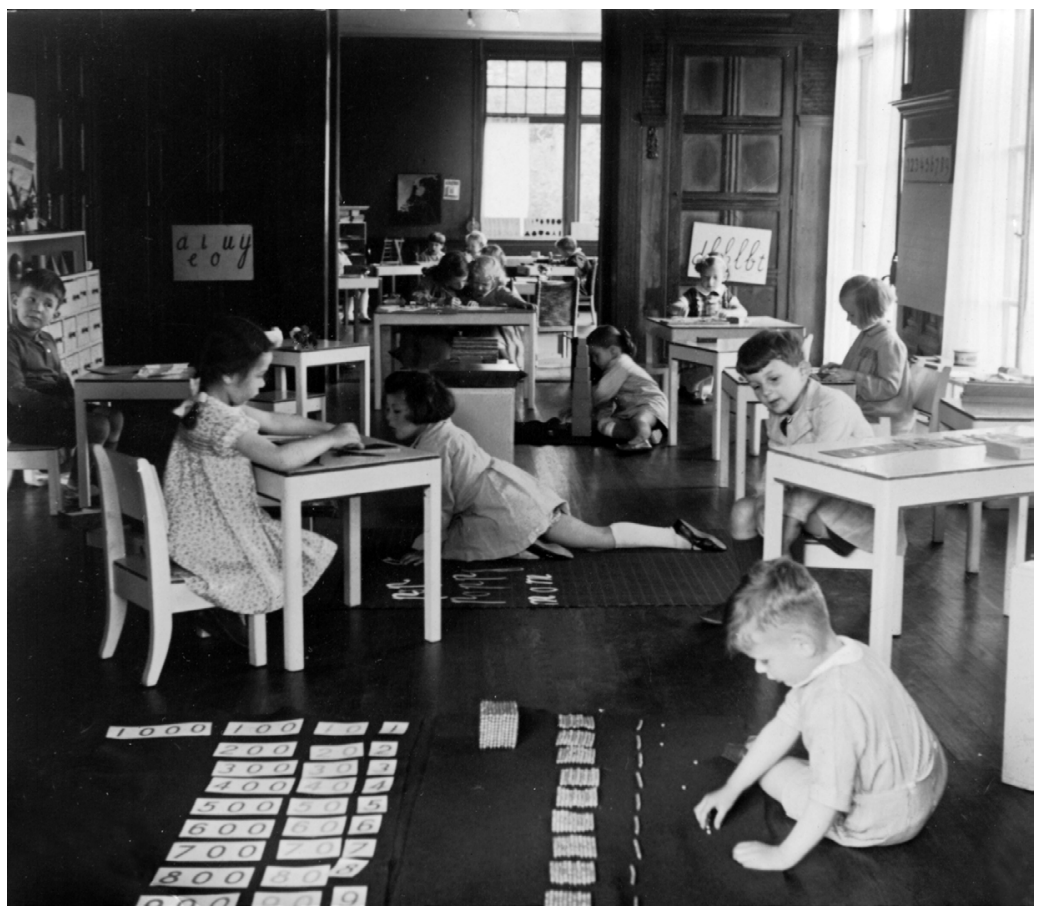

FONTE: Disponível em: https://sinteno.weebly.com/blog/nova-educacao-na-pratica-metodomontessori. Acesso em: 04 jan. 2019.

Para Oliveira e Bortoloti,

Através desses materiais é possível atrair a inteligência da criança para coisas e fenômenos, além disso, a apresentação do material pode ser individual sem a necessidade de uma lição verbal. Deve ser apresentado lentamente, com clareza a fim de que a criança possa sozinha, perceber o movimento e executá-lo corretamente por todo tempo que queira. Os erros eventuais, provocados pela falta de experiência, em sua grande maioria, devem ser corrigidos pela própria criança, exceto em situações de uso indevido, desordenadamente. Nesse caso, o professor pode conduzir para que faça o uso adequado (OLIVEIRA; BOTOLOTI, 2012, p. 416). 
Esse material auxilia no ensino e aprendizagem da Matemática, junto às crianças que apresentavam dificuldades de aprendizagem. Diante do sucesso que teve o material dourado, os professores brasileiros começaram a utilizá-lo em sala de aula para trabalhar as estruturas do Sistema de Numeração Decimal, os algoritmos das quatro operações fundamentais, conceitos geométricos, frações, números decimais, porcentagem, áreas e volumes.

No ensino tradicional, as crianças acabam "dominando" os algoritmos a partir de treinos cansativos, mas sem conseguirem compreender o que fazem. Com o material dourado a situação é outra: as relações numéricas abstratas passam a ter uma imagem concreta, facilitando a compreensão. Obtém-se, então, além da compreensão dos algoritmos, um notável desenvolvimento do raciocínio e um aprendizado bem mais agradável.

Era conhecido como "Material das Contas Douradas" e sua forma permitia que as próprias crianças produzissem as dezenas e centenas. A imprecisão das medidas dos quadrados e cubos se constituía em um problema ao realizar atividades com números decimais. Por isso, Lubienska de Lenval fez uma modificação, construindo em madeira, na forma que encontramos hoje. É importante porque as relações numéricas abstratas passam a ter uma imagem concreta, facilitando a compreensão, o desenvolvimento do raciocínio lógico e um aprendizado bem mais agradável.

Permite que os alunos dos anos iniciais do Ensino Fundamental consigam entender melhor as operações de adição com trocas e a subtração com agrupamento, além de possibilitar que ainda têm certa dificuldade de entender a passagem do abstrato para o concreto, uma aprendizagem com compreensão e mais eficácia.

Como exemplo, o professor poderá mediar atividades questionando: $\mathrm{O}$ que é um número decimal? Que fração do inteiro representa cada cubinho? Quantos centésimos formam um inteiro? Quantos centésimos precisamos para formar 1 décimo? Quantos centésimos precisamos para formar 8 décimos? Com 1 décimo, quantos centésimos podemos fazer? Quantos décimos tem 2 inteiros? Em 2 décimos, há quantos centésimos?

Além disso, é possível organizar atividades para comparar números decimais, a fim de que ele entenda o valor posicional dos algarismos, representando os valores indicados com o material dourado. É plausível também realizar operações com números decimais, utilizando o Material, de modo que o aluno consiga representar os valores indicados em cada operação por suas frações decimais, depois devem ser representadas com o material dourado e então finalmente calculadas. Exemplo: 1,3 + 3,02 = 4,32

Enfim, Maria Montessori com o objeto de estudo acerca da aprendizagem da criança pesquisou, cientificamente, pois "procurou a melhor maneira possível 
de ajudar a criança a se desenvolver positivamente em todas as dimensões [...] observando a criança em diferentes situações e em diferentes etapas da sua vida" (DUBUC, 2010, p. 204).

Maria Montessori considerava fundamental a comunicação entre os seres humanos, a fim de que a atenção destinada à criança seja feita com amor, uma vez que "sem amor, a vida não é possível" (DUBUC, 2010, p. 208).

Ela considerava também que enquanto adultos devemos reconhecer quatro períodos de desenvolvimento do ser humano (do 0 aos 24 anos). No primeiro período ( 0 a 6 anos) a exploração é sensorial, depois a imaginação vem à tona. A educadora foi criticada, mas sua teoria atraiu muitos, com a simplicidade do uso do material didático com as crianças, de modo que na Pedagogia Montessoriana a "criança é ativa e o ensino é aberto" (DUBUC, 2010, p. 216).

\section{Considerações finais}

Os olhares que apresentamos nesse artigo acerca de uma pedagogia com números no pensamento de Comenius, Pestalozzi e Montessori nos mostraram que a Matemática no pensamento educacional desses pensadores foi abordada como um sistema de linguagem que, em vez de letras e palavras, utiliza-se símbolos numéricos. Mostraram ainda que há uma circulação de ideias entre o pensamento educacional dos três professores, no que diz respeito ao ensino do concreto para o abstrato, e ao uso de materiais didáticos no ensino da Matemática.

Vale dizer ainda, que nos métodos proposto por Comênius, Pestalozzi e Maria Montessori a Matemática está associada às atividades práticas e gradativas, de modo que, valoriza-se a participação ativa das crianças, o seu crescimento subjetivo, dentro do processo de construção da sua aprendizagem.

Portanto, esses métodos precisam ser divulgados, estudados na formação do professor de Matemática, até para que ele responda como se ensina Matemática, quem ensina Matemática e que Matemática se ensina, na perspectiva de que entendamos que a Pedagogia de Comenius, de Pestalozzi e Montessoriana não se acabaram, até porque, cada um de nós, sejam futuros professores de Matemática ou Pedagogos, temos como um dos objetivos de ensino, o que dizia Montessori "redescobrir o segredo da infância e construir a partir da criança". 


\section{REFERÊNCIAS}

ARCE, Alessandra. A pedagogia na "era das revoluções": uma análise do pensamento de Pestalozzi e Froebel. Campinas: Autores Associados, 2002.

BOTO, Carlota. A liturgia escolar na idade moderna. Campinas: Papirus, 2017.

CAMBI, Franco. História da Pedagogia. São Paulo: Fundação Editora da UNESP (FEU), 1999.

CHAVANNES, Daniel A. Exposé de la méthode élémentaire de H Pestalozzi. Vevey: Loertscher et Fils, 1805.

CHAVANNES, Daniel A. Exposé de la méthode élémentaire de H. Pestalozzi, suivi d'une notice sur les travaux de cet homme célèbre, son institut et ses principaux collaborateurs. Paris: Levrault-Schoell, 1809.

COMENIUS, João A. Didática Magna. Tratado da Arte Universal de Ensinar tudo a todos. Lisboa: Fundação Calouste Gulbenkian, 1966.

COSTA, David A. da. As concepções e contribuições de Pestalozzi, Grube, Parker e Dewey para o ensino da aritmética no nível elementar: o conceito de número. Hist. Educ., Santa Maria, v. 18, n. 42, p. 37-59, abr. 2014. Disponível em: http://www.scielo. br/scielo.php?script=sci_arttext\&pid=S2236-34592014000100003\&lng=en\&nrm=iso. Acesso em: 08 abr. 2018 .

COSTA, Magda S. P. Maria Montessori e seu método. Linhas críticas, Brasília, v. 7, n. 13 , p. 305-320, 2001.

COUSINET, Roger. A Educação Nova. São Paulo: Companhia Editora Nacional, 1959.

DUBUC, Benoit. Maria Montessori: a criança e sua educação. In: GAUTHIER, Clemort; TARDIFF, Maurice (org.). A Pedagogia: teorias e práticas da antiguidade aos nossos dias. Petrópolis: Vozes, 2010.

EBY, Frederick. História da educação moderna: teoria, organização e prática educacionais. Porto Alegre: Globo, 1962.

FALZETTA, Ricardo. O uso de peças no lugar de números: fundamentos teóricos e metodologia de matemática 1. Rio de Janeiro: Nova Escola, 1997.

FOSCHI, Renato. Maria Montessori. Roma: Ediesse, 2012.

GALLEGO, María Dolores C. La metodologia de la aritmética em los comienzos de las escuelas normales (1838-1868) y sus antecedentes. Murcia: Departamento de Didáctica de las Ciencias Matemáticas y Sociales-Universidad de Murcia, 2005.

GAUTHIER, Clemort. Da pedagogia tradicional à pedagogia nova. In: GAUTHIER, Clemort; TARDIF, Maurice (org.). A pedagogia: teorias e práticas da Antiguidade aos nossos dias. 3. ed. Petrópolis: Vozes, 2014. 
INCONTRI, Dora. Pestalozzi, Educação e ética. São Paulo: Scipione, 1996.

MESQUIDA, Peri. O método em Pestalozzi: a matemática como caminho para a verdade. Revista de História da Educação Matemática, São Paulo, v. 2, n. 1, p. 19-39, 2016.

MONTESSORI, Maria. Pedagogia Científica: a descoberta da criança. São Paulo: Flamboyant, 1965.

MONTESSORI, Maria. The montessori method. London: Transaction publishers, 2013. NARODOWSKI, Mariano. Comenius \& a Educação. Belo Horizonte: Autêntica, 2001.

OLIVEIRA, Kely V. G.; BORTOLOTI, Roberta D’A. M. Método montessoriano: contribuições para o ensino-aprendizagem da matemática nas séries iniciais. Revista eventos pedagógicos, Sinop, v. 3, n. 3, p. 410-426, 2012.

OLIVEIRA, Marcus A. Pedagogia Intuitiva da Escola Elementar de Pestalozzi: como se ensinava Aritmética? Bolema, Rio Claro (SP), v. 31, n. 59, p. 1005-1031, 2017.

PESTALOZZI, Johann H. et al. Écrits sur la méthode. Le Mont-sur-Lausanne: Ed. Loisirs et pédagogie (LEP), 2009.

PESTALOZZI, Johann H. Cómo Gertrudis enseña a sus hijos: cartas sobre la educación de los niños. Libros de educación elemental (prólogos). México: Porrúa, 1980.

RÖHRS, Hermann. Maria Montessori. Recife: Fundação Joaquim Nabuco, Editora Massangana, 2010. (Coleção Educadores).

SOËTARD, Michel. Johann Pestalozzi. Recife: Fundação Joaquim Nabuco, Editora Massangana, 2010. (Coleção Educadores).

TRÖHLER, Daniel. Pestalozzi y la educacionalización del mundo. Barcelona: Octaedro Editorial, 2014.

Texto recebido em $05 / 01 / 2019$.

Texto aceito em 02/04/2020. 